\title{
Research Article \\ Effect of Gurney Flap Geometry on a S809 Airfoil
}

\author{
Li-Shu Hao and Yong-Wei Gao \\ National Key Laboratory of Science and Technology on Aerodynamic Design and Research, Northwestern Polytechnical University, \\ Xi'an 710072, China
}

Correspondence should be addressed to Li-Shu Hao; haolishu@nwpu.edu.cn

Received 29 January 2019; Revised 29 April 2019; Accepted 3 June 2019; Published 18 July 2019

Academic Editor: Jose Carlos Páscoa

Copyright (c) 2019 Li-Shu Hao and Yong-Wei Gao. This is an open access article distributed under the Creative Commons Attribution License, which permits unrestricted use, distribution, and reproduction in any medium, provided the original work is properly cited.

In this paper, the effect of Gurney flap shapes on wind turbine blade airfoil S809 has been studied by numerical simulation. First, the O-type grid is used in the numerical simulation. By comparing with experimental data, such as the lift force, the drag coefficient, and the pressure distribution, the accuracy of the simulation method is validated. Second, the research on the widths of three kinds of rectangular Gurney flaps at the trailing edge of the S809 airfoil is carried out. Rectangular Gurney flaps can considerably increase the lift in both the linear and nonlinear sections, and the maximum lift coefficient can be increased by 20.65\%. In addition, the drag and the pitching moment are increased. However, the width of the rectangular Gurney flap has a small impact on the lift, the drag, and the pitching moment. Finally, the effects of rectangular and triangular Gurney flaps on the aerodynamic characteristics of the S809 airfoil are compared. The results show that the triangular flaps can obtain an increase of maximum lift coefficient by $28.42 \%$, which is better than $16.31 \%$ of the rectangular flaps.

\section{Introduction}

With the development of renewable energy, the utilization of wind power has undergone impressive progresses as a major clean energy source. Blades are the key component of a wind turbine to capture the wind energy, while airfoils are the core element of a blade. Therefore, the aerodynamic characteristics of the airfoil have a huge impact on the overall aerodynamic characteristics of the wind turbine. Questions such as how to improve the aerodynamic characteristics of the airfoil, how to increase the ability of the wind turbines to catch wind, and how to control the local loads on the blades have remained hot issues for researchers worldwide.

Gurney flaps can significantly change the aerodynamic characteristics of airfoils. An experimental study on the installation of Gurney flaps at the trailing edge of the airfoil was first carried out by Liebeck [1] (see Figure 1). His research indicated that Gurney flaps could increase the circulation and the lift of the airfoil. Later, researchers from various countries conducted a large amount of research on the mechanisms and the control effect of Gurney flaps using wind tunnel tests and numerical simulations.
Gurney flaps have been widely used and studied in airfoil static/dynamic stall control [2-5], flutter control [6], flapping airfoil control [7], ground effects [8], and rotor blade load control [9-13]. In these applications, the increases in the lift and the drag are closely related to airfoils, flow conditions, and the flap geometry.

Wang et al. [14] discussed the high-lift mechanism of Gurney flaps and their applications in low-speed airfoils, supercritical airfoils, lifting devices, and delta wings. For low-speed airfoils, the effects of the Gurney flap height, the mounting position, the mounting angle, and the layout on the lift, the drag, and the pitching moment are also discussed. Cole et al. [15] discussed the effects of Gurney flap heights and positions on the aerodynamic characteristics of five different airfoils, showing that the lift-increasing effects of different Gurney flap heights and installation locations for different airfoils are not the same. Myose et al. [16] discussed the effects of Gurney flaps on the aerodynamic characteristics on single or multielement airfoils, three-dimensional wings, and reflection plane models, indicating that different Gurney flap heights have significant effects on both the lift and the drag coefficients of the model. Nikoueeyan et al. [17] carried 


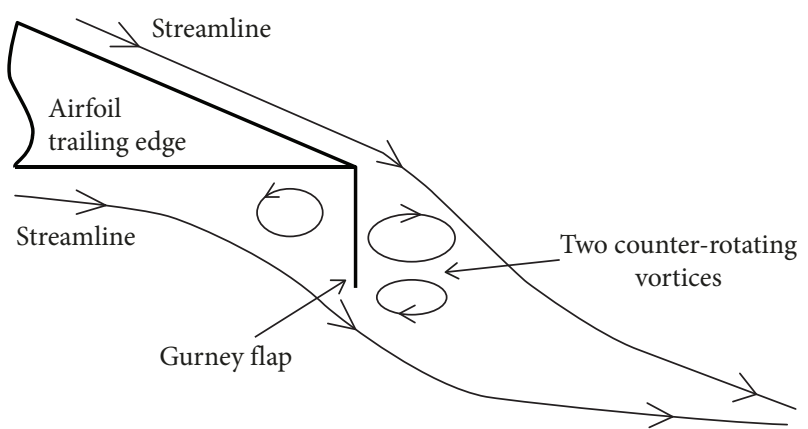

Figure 1: Hypothesized Gurney flap trailing-edge flow conditions of an airfoil.

out wind tunnel tests on Gurney flaps mounted at the blunt trailing edge of the wind turbine blade airfoil DU97-W-300, indicating that Gurney flaps on the lower surface of the airfoil at the trailing edge can increase the lift, while those on the upper surface can reduce the lift. He et al. [18] investigated the Gurney flap lift-enhancement for a low Reynoldsnumber airfoil with a numerical simulation, and the flap heights varied from $0.25 \% \mathrm{c}$ to $3 \% \mathrm{c}$. The paper presented the pressure distribution, the flow field, and the drag coefficient on the airfoil with Gurney flaps. Graham et al. [19] investigated the effect of the Gurney flap thickness on the SD7062 airfoil performance with an experimental method, showing that the lift augmentation due to the flap increased with the flap height and decreased with the flap thickness.

In summary, the research on Gurney flaps mostly uses the traditional rectangular flaps focusing on flap heights, flap mounting positions, and installation angles. Presented in this paper is a study focusing on the effect of the Gurney flap shape on wind turbine blade airfoil S809. The first purpose is to investigate the influence of the Gurney flap width on the aerodynamic performance of the S809 airfoil and reveal the flow details of the airfoil. The second purpose is to compare the effects of the traditional rectangular Gurney flap and the triangle Gurney flap on the aerodynamic performance of the S809 airfoil.

\section{Numerical Method and Validation}

The numerical simulation of the S809 wind turbine airfoil is performed by CFD++ software. The steady ReynoldsAveraged Navier-Stokes (RANS) equations and the SpalartAllmaras one-equation turbulence model are used to carry out the numerical study. The Reynolds number is $10^{6}$, the Mach number is 0.0716 , and the range of the angle of attack is $-2^{\circ} \sim 20^{\circ}$. An O-shaped grid is used with a far-field radius of $45 \mathrm{c}$, as shown in Figure 2. The normal layers in an O-mesh are 146, and the wrap-around points are 400 . The first layer spacing is $1 \times 10^{-5} \mathrm{c}$ and total number of cells is $5.8 \times 10^{4}$. The boundary conditions are the nonslip wall boundary condition and the far-field boundary condition based on the characteristics of the flow.

To validate the numerical method, the experimental data of the S809 airfoil provided by Delft University of Technology [20] are compared with the numerical results.

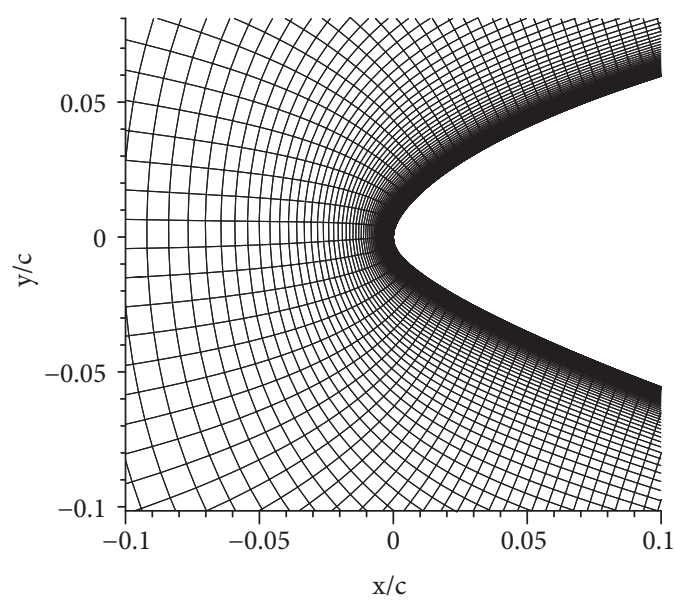

(a) Leading-edge region grid schematic diagram

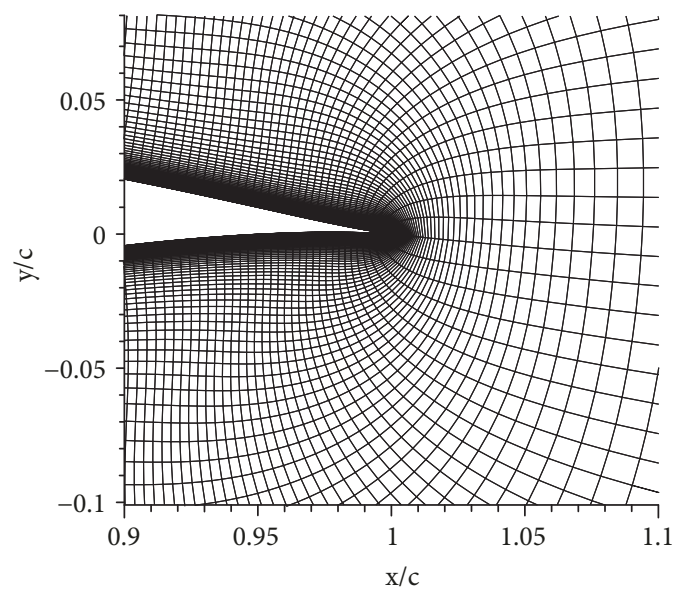

(b) Trailing-edge region grid schematic diagram

FIgURE 2: O-mesh for the $\$ 809$ airfoil.

The Mach number $(\mathrm{Ma}=0.0716)$ and the Reynolds number $\left(\operatorname{Re}=1 \times 10^{6}\right)$ for the numerical simulation are the same as those of the wind tunnel test. The chord of the S809 airfoil is $600 \mathrm{~mm}$. The simulation results are compared with the experimental data in Figure 3. The results show that the lift and pitching moment agree rather well with the measurement for the range of angles of attack from $-2^{\circ}$ to $8^{\circ}$. After the flow separation occurrence, the lift is a little overpredicted but within an acceptable degree and the variation trend is well captured. The drag is obviously overpredicted. The possible reason is that the $\$ 809$ is a laminar airfoil, and there probably exits transition on the airfoil surface in the experiment. The numerical simulations are carried out under the assumption of full turbulence which causes the drag larger than that of a laminar flow. So, the drag could be overpredicted. Overall, the numerical results agree fairly well with the experimental data, indicating the accuracy of the numerical method in this paper. Xu et al. [21] also used the similar validation strategy as this paper to validate their numerical results. Therefore, the subsequent research in the present paper will use the full turbulence model to carry out numerical simulations. 


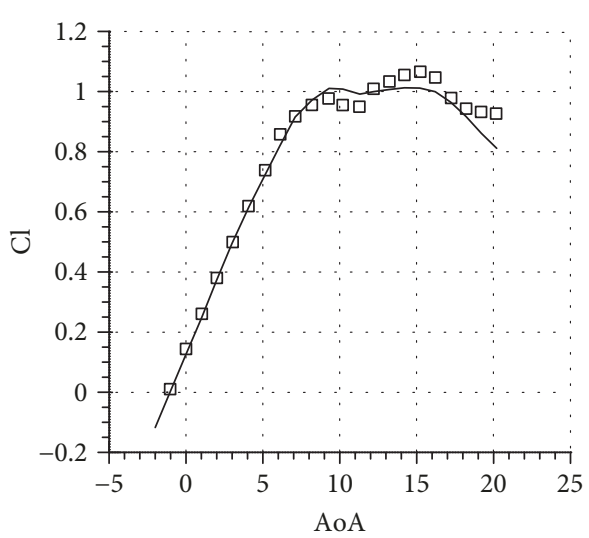

Experiment

(a) Lift coefficient

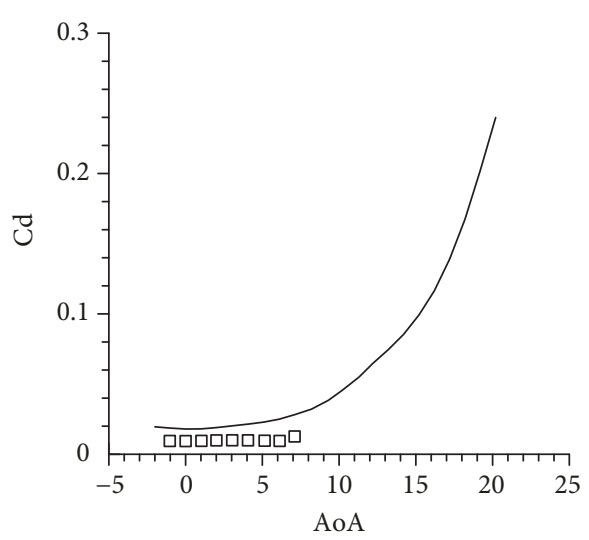

․ Experiment

$\longrightarrow$ CFD

(b) Drag coefficient

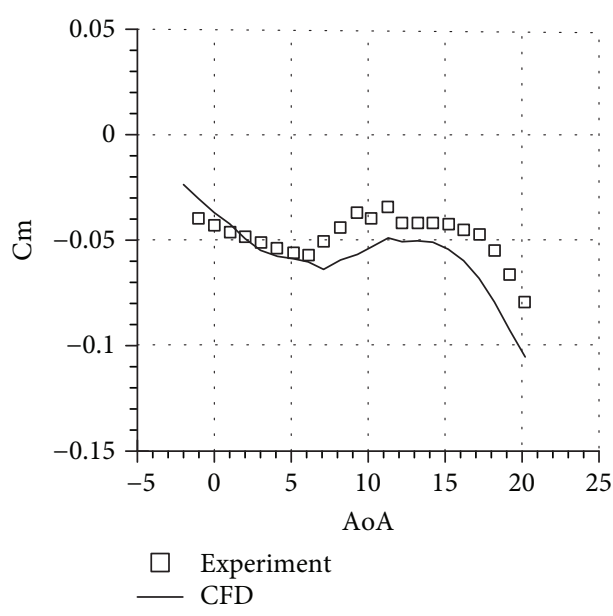

(c) Moment coefficient

FIGURE 3: Comparison of aerodynamic coefficients of experimental data and CFD simulations.

\section{Results and Discussion}

Tsai et al.'s work [11] shows that the Gurney flap mainly changes the effective camber of the airfoil, which has a significant impact on the small AoA. Hence, the range of the angle

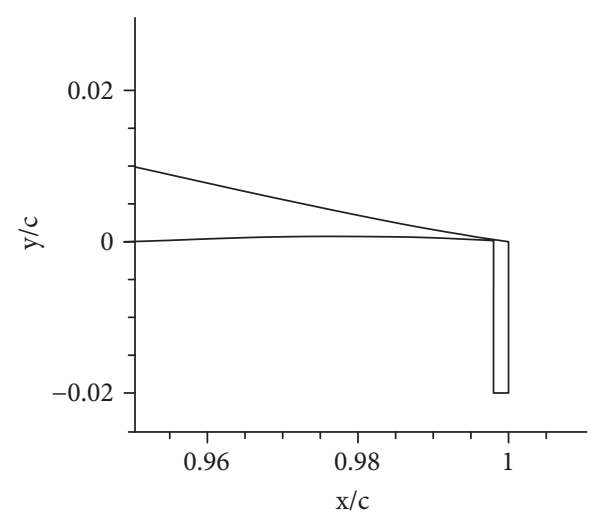

(a) GF_W2

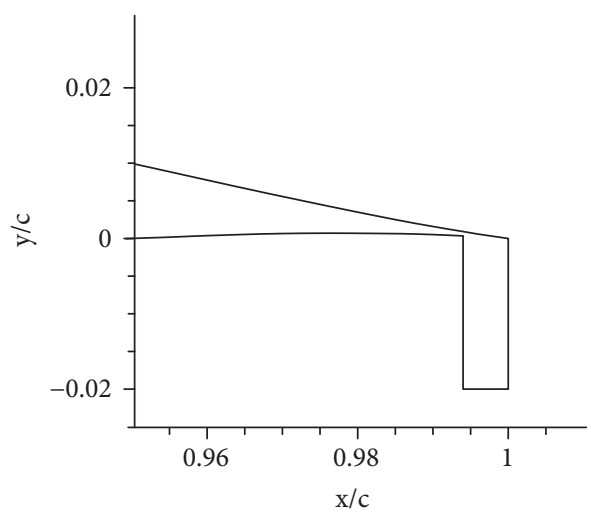

(b) GF_W6

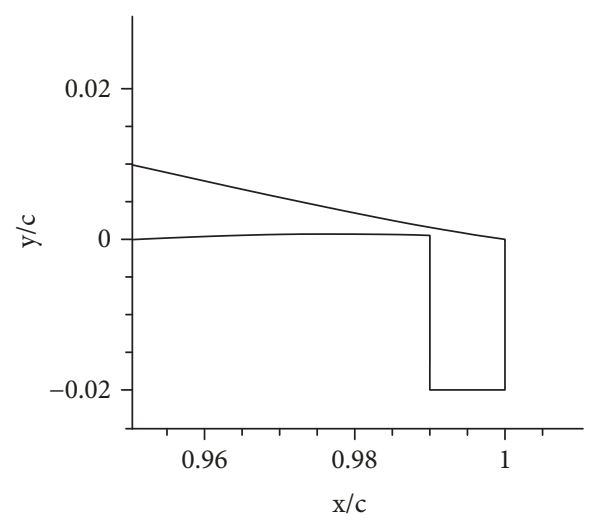

(c) GF_W10

Figure 4: Schematic diagram of the three Gurney flap widths.

of attack for subsequent numerical simulations is $-2^{\circ} \sim 16^{\circ}$. In order to study the influence of Gurney flaps on the aerodynamic characteristics of the airfoil, the simulation conditions are set as $\mathrm{Re}=1 \times 10^{6}$ and $\mathrm{Ma}=0.0716$.

3.1. Effect of Gurney Flap Width. In this section, we discuss the effect of the flap width on the aerodynamic characteristics of the airfoil S809, when rectangular Gurney flaps are mounted at the trailing edge of the airfoil. Three Gurney flap widths are displayed in Figure 4. All Gurney flaps have a height of $12 \mathrm{~mm}(2 \% \mathrm{c})$, and their widths are, respectively, $0.2 \%$ c, $0.6 \%$ c, and $1.0 \%$ c, which are denoted as "GF_W2," 
"GF_W6," and "GF_W10," respectively. The clean airfoil without Gurney flaps is denoted as "Baseline".

Figure 5 exhibits the aerodynamic performances of the airfoils with different Gurney flap widths. As can be seen, the Gurney flaps with widths of $0.2 \% c, 0.6 \% c$, and $1.0 \% c$ can significantly increase both the lift of the linear and the nonlinear sections. The lift coefficients at $\mathrm{AoA}=1.03^{\circ}$ are, respectively, increased by $102.33 \%, 91.79 \%$, and $89.23 \%$, and those at $\mathrm{AoA}=7.1^{\circ}$ are, respectively, increased by $28.33 \%, 26.97 \%$, and $23.36 \%$. Furthermore, the maximum lift coefficients are, respectively, increased by $20.65 \%, 20.29 \%$, and $16.31 \%$. Therefore, the Gurney flap can generate higher lift coefficients, as the flap thickness decreases, which is consistent with Graham et al.'s conclusion [19]. A substantial increase in the lift, the drag, and the pitching moment is observed; however, the change in Gurney flap widths has a small effect on them.

In order to study the effect of the width of the flap on the lift-to-drag ratio of the S809 airfoil, the percentage increase in the lift-to-drag ratio is defined here, i.e., $\left(\mathrm{K}_{\mathrm{GF}}-\mathrm{K}_{\mathrm{Baseline}}\right)$ / $\mathrm{K}_{\text {Baseline, where " }} \mathrm{K}_{\mathrm{GF}}$ " and " $\mathrm{K}_{\mathrm{Baseline}}$ " respectively, represent the lift-to-drag ratio of the airfoil with and without Gurney flap. The effect of GF widths on the lift-to-drag ratio for the S809 airfoil is shown in Table 1. The results show that the Gurney flaps of different widths can increase the lift-todrag ratio in the linear section. At high angles of attack, the lift-to-drag ratio is reduced. It can be seen from Figure 5 that the drag is small in the linear section, the lift-enhancement effect of Gurney flap is remarkable, and the lift-to-drag ratio is increased. The Gurney flap can also increase the lift at high angle of attack, but the drag is significantly increased, resulting in a decrease in the lift-to-drag ratio.

Comparison of the streamline over the airfoil trailing edge under different Gurney flap widths at $\mathrm{AoA}=1.03^{\circ}$ is displayed in Figure 6. The results show that the fluid near the trailing edge without Gurney flaps flows smoothly past the trailing edge. The Gurney flap at the trailing edge of the airfoil causes a large vortex in front of the flap and a pair of opposite vortices behind the flap, and the streamlines of the upper and lower surfaces at the airfoil trailing edge converge not far behind the opposite vortices. This indicates that the vortex structure downstream of the Gurney flap can increase the effective camber of the airfoil.

Figure 7 presents the comparison of surface pressure distributions for different Gurney flap widths. As can be seen in the figure, Gurney flaps can significantly reduce the pressure on the upper surface, while increase that on the lower surface. Thus, the integral area and the suction peak are both enhanced. The influence of Gurney flap widths on the pressure distribution is small, which is consistent with the lift curves in Figure 5(a).

3.2. Effect of Gurney Flap Geometry Shape. In this section, we discuss the effect of shapes of Gurney flaps on the aerodynamic characteristics of the airfoil S809. The Gurney flaps in different shapes with the width of $1.0 \% \mathrm{c}$ and the same height as GF_W10 are presented in Figure 8. We first keep the leading edge of the rectangular Gurney flap and cut half of the Gurney flap to form a beveled triangular flap, labeled

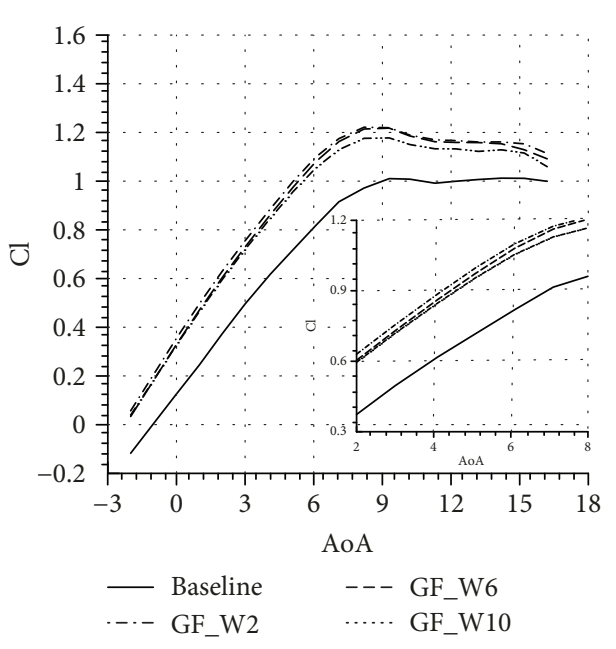

(a) Lift coefficient

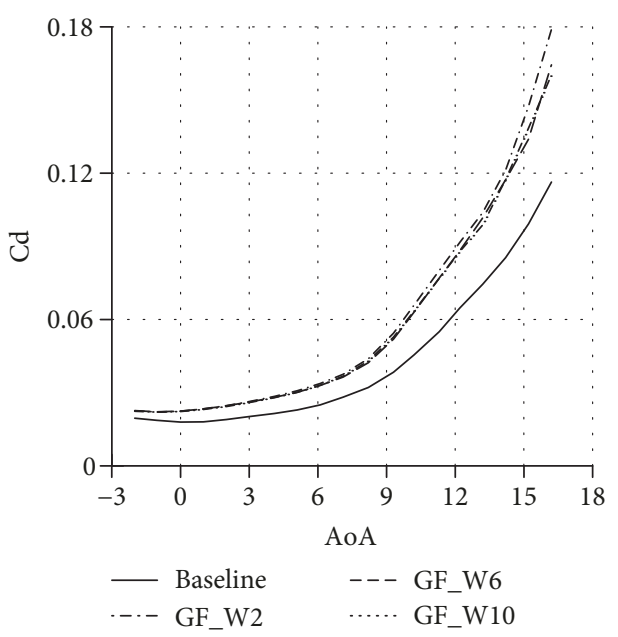

(b) Drag coefficient

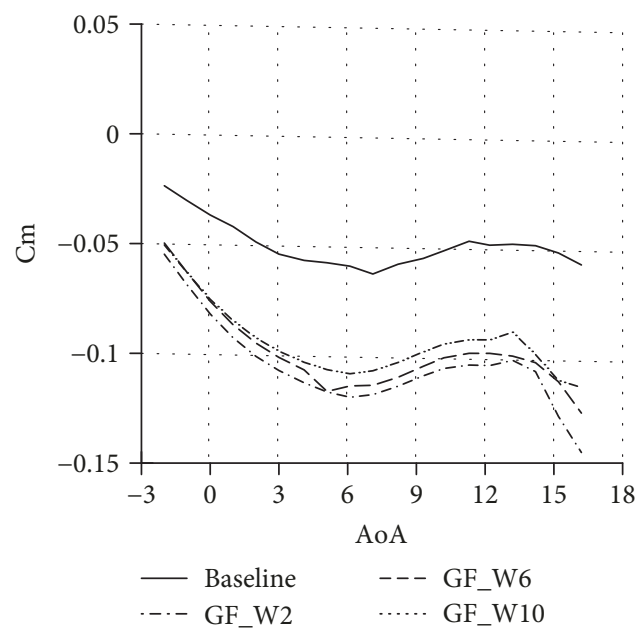

(c) Moment coefficient

FIGURE 5: Comparison of aerodynamic coefficients of the airfoils under different Gurney flap widths.

"GF_W10_A." Then, the trailing edge of the rectangular Gurney flap is kept, and half of the Gurney flap is cut to form a beveled triangular flap, labeled "GF_W10_C." Finally, we 
TABLE 1: Effect of GF widths on the lift-to-drag ratio for the S809 airfoil.

\begin{tabular}{lccc}
\hline AoA & GF_W2 & GF_W6 & GF_W10 \\
\hline $1.03^{\circ}$ & $56.15 \%$ & $48.2 \%$ & $47.54 \%$ \\
$3.04^{\circ}$ & $16.83 \%$ & $13.64 \%$ & $12.92 \%$ \\
$5.15^{\circ}$ & $3.51 \%$ & $3.15 \%$ & $1.29 \%$ \\
$7.1^{\circ}$ & $-3.7 \%$ & $-1.74 \%$ & $-5.5 \%$ \\
$9.27^{\circ}$ & $-14.77 \%$ & $-10.89 \%$ & $-15.22 \%$ \\
$11.27^{\circ}$ & $-19.0 \%$ & $-16.28 \%$ & $-18.23 \%$ \\
\hline
\end{tabular}

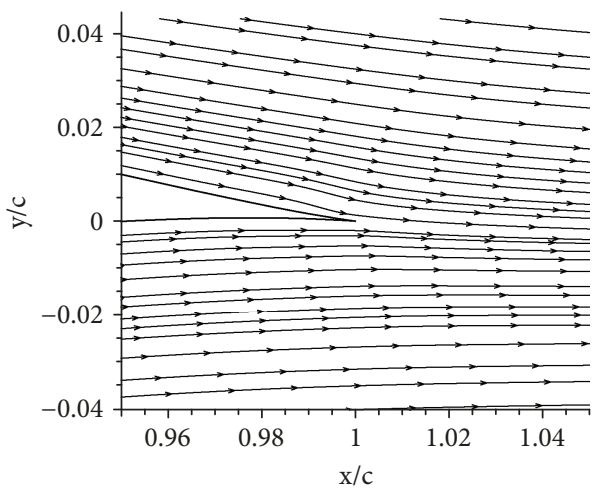

(a) Baseline

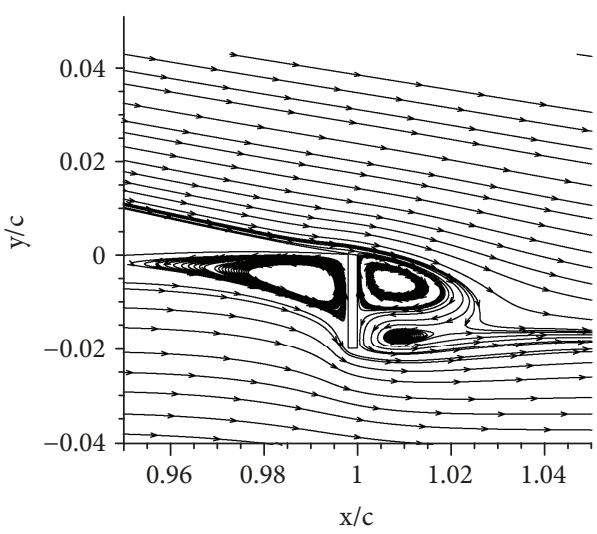

(b) GF_W2

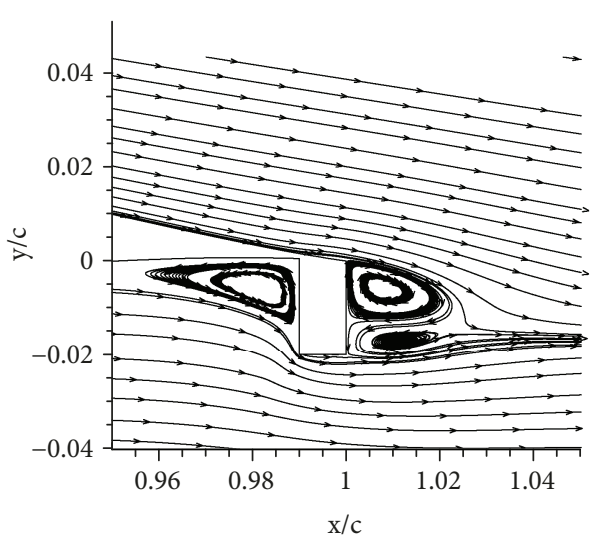

(c) GF_W10

FIGURE 6: Comparison of the streamline at the airfoil trailing edge under different Gurney flap widths $\left(\mathrm{AoA}=1.03^{\circ}\right)$.

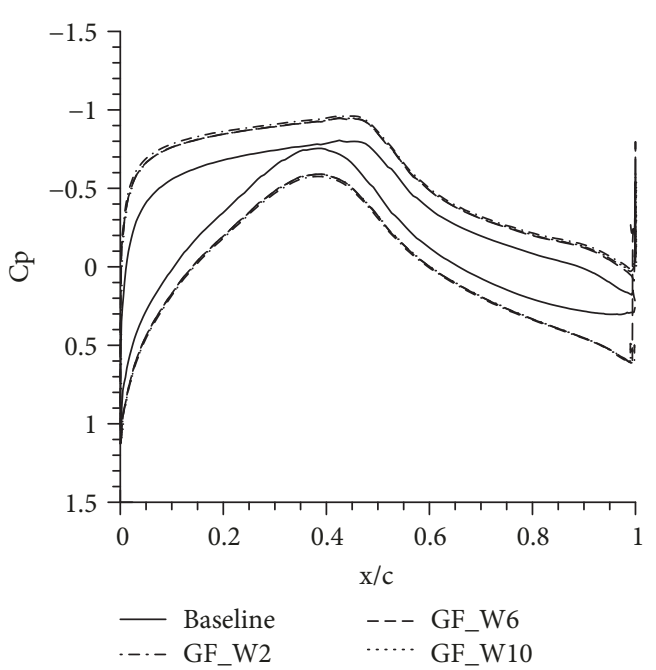

(a) $\mathrm{AoA}=1.03^{\circ}$

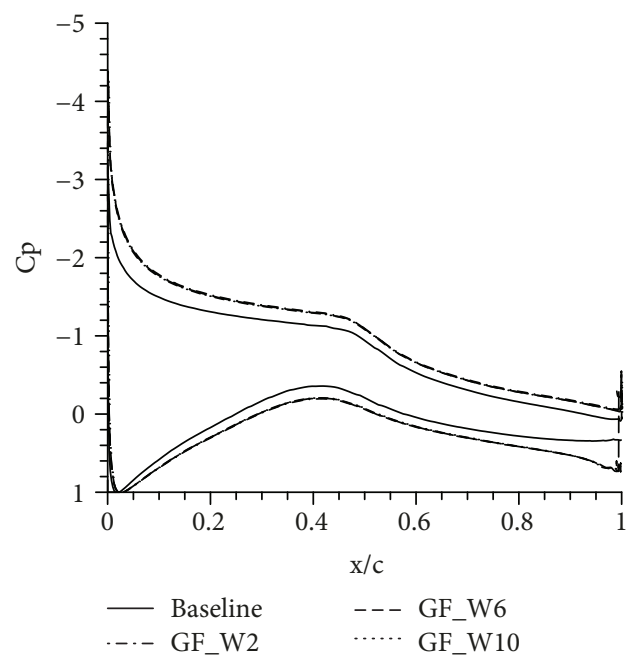

(b) $\mathrm{AoA}=7.1^{\circ}$

FIGURE 7: Pressure coefficient distribution comparison of the airfoil with different Gurney flap widths.

remove the leading and the trailing edges of the rectangular flap and take the midpoint of the bottom of the rectangular flap to form the isosceles triangle flap, labeled "GF_W10_B."

Figure 9 presents the aerodynamic performances of the airfoils with different Gurney flap shapes. The results show that the lifts of both the linear and nonlinear sections of the airfoil with the Gurney flaps in three shapes are all improved to a certain extent, compared with Baseline. The lift coefficients at $\mathrm{AoA}=1.03^{\circ}$ are increased by $100.86 \%, 108.52 \%$, and $114.81 \%$ for GF_W10_A, GF_W10_B, and GF_W10_C, respectively, and the lift coefficients are, respectively, increased by $31.73 \%, 34.57 \%$, and $36.25 \%$ at $\mathrm{AoA}=7.1^{\circ}$. Moreover, the maximum lift coefficients are increased by $24.78 \%, 26.90 \%$, and $28.42 \%$, respectively. This illustrates that the effect of the triangle Gurney flap is remarkably better than the rectangular one and GF_W10_C is the best.

The effect of GF geometry shapes on the lift-to-drag ratio for the $\$ 809$ airfoil is shown in Table 2. The results show that the Gurney flaps of different geometry shapes can increase 


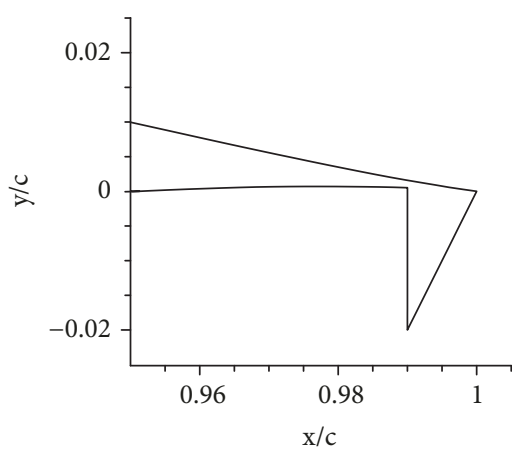

(a) GF_W10_A

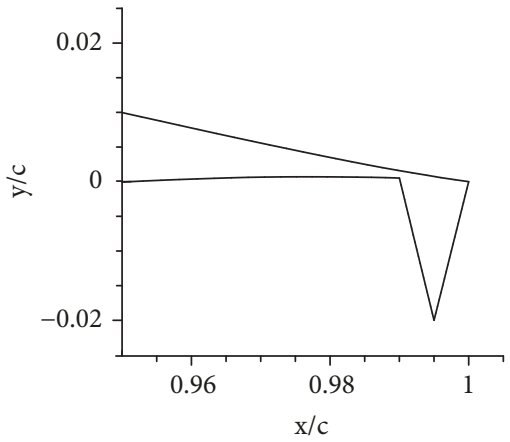

(b) GF_W10_B

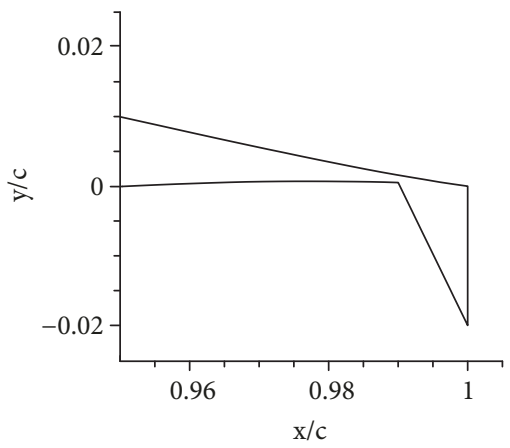

(c) GF_W10_C

FIGURE 8: Schematic diagram of various Gurney flap shapes.

the lift-to-drag ratio in the linear section. The flaps also can increase the lift-to-drag ratio of the airfoil when there is a slight separation flow over the airfoil surface (e.g., AoA $=7.1^{\circ}$ ). By comparing the data in Tables 1 and 2, it can be found that the lift-enhancement effect of the triangular Gurney flaps is better than that of the rectangular Gurney flaps and GF_W10_C is the best.

The comparison of the streamlines over the airfoil trailing edge with different Gurney flap shapes at $\mathrm{AoA}=7.1^{\circ}$ is depicted in Figure 10. There is a distinct separation vortex near $0.95 \mathrm{c}$ at the trailing edge without Gurney flaps. For rectangular Gurney flap GF_W10, three separation vortices appear on the upper surface of the trailing edge, before and after the flaps. With respect to the baseline airfoil, the separation-vortex region of the trailing edge on the upper surface is reduced. For triangular Gurney flap GF_W10_C, the separation vortex on the upper surface of the trailing edge disappears completely and that in front of the flaps is

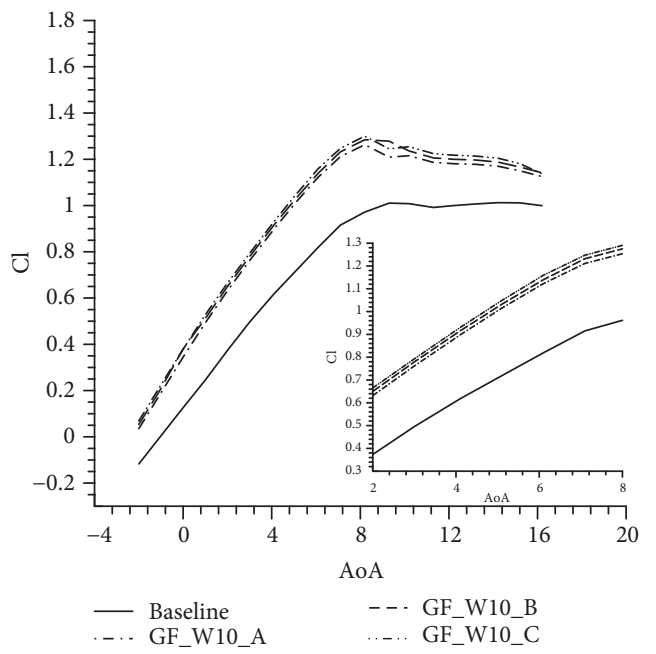

(a) Lift coefficient

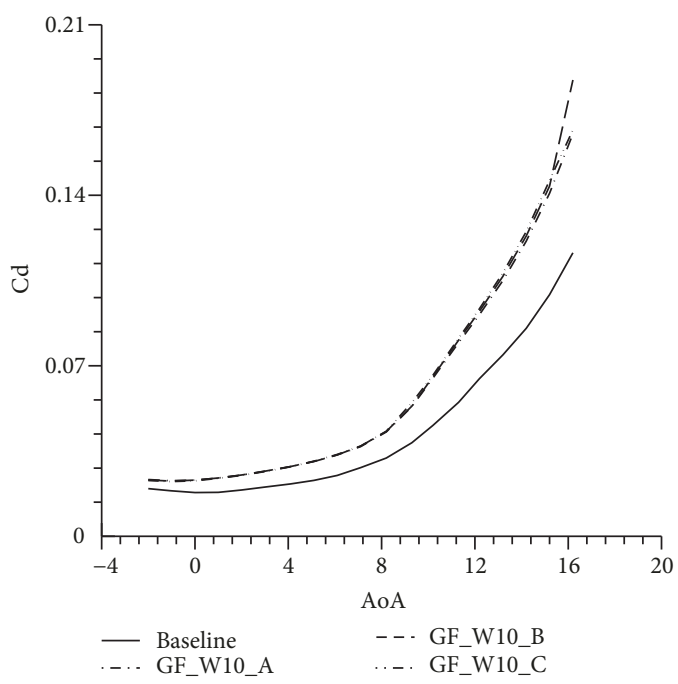

(b) Drag coefficient

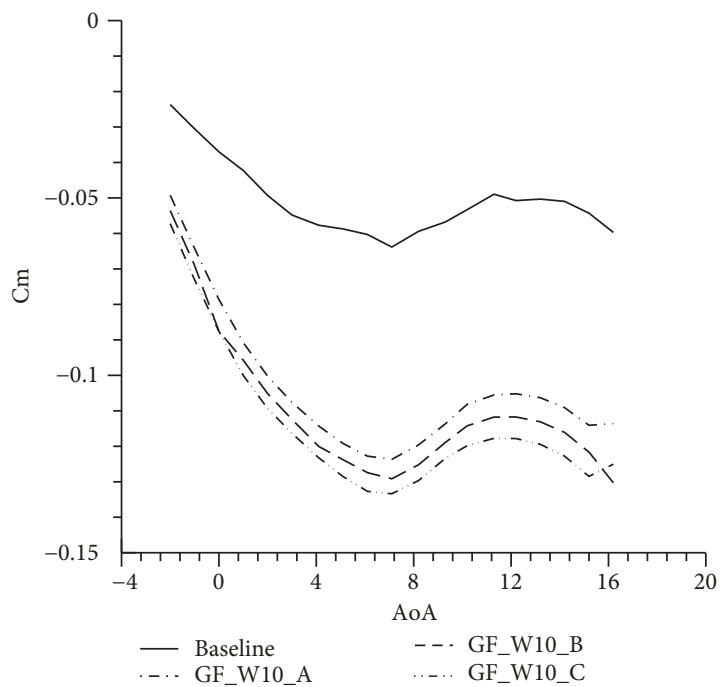

(c) Moment coefficient

Figure 9: Aerodynamic coefficient comparison of the airfoils under different Gurney flap shapes. 
TABLE 2: Effect of GF geometry shapes on the lift-to-drag ratio for the $\mathrm{S} 809$ airfoil.

\begin{tabular}{lccc}
\hline AoA & GF_W10_A & GF_W10_B & GF_W10_C \\
\hline $1.03^{\circ}$ & $51.39 \%$ & $57.28 \%$ & $63.03 \%$ \\
$3.04^{\circ}$ & $16.19 \%$ & $18.85 \%$ & $21.65 \%$ \\
$5.15^{\circ}$ & $5.34 \%$ & $7.25 \%$ & $8.54 \%$ \\
$7.1^{\circ}$ & $1.22 \%$ & $2.34 \%$ & $3.69 \%$ \\
$9.27^{\circ}$ & $-13.78 \%$ & $-9.1 \%$ & $-13.76 \%$ \\
$11.27^{\circ}$ & $-17.18 \%$ & $-16.91 \%$ & $-16.45 \%$ \\
\hline
\end{tabular}

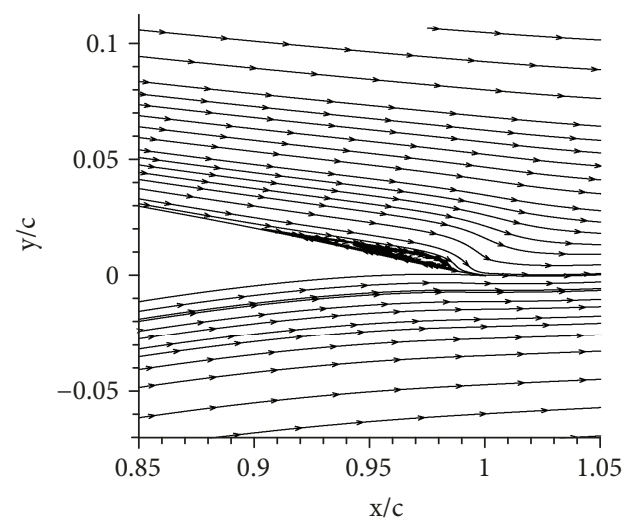

(a) Baseline

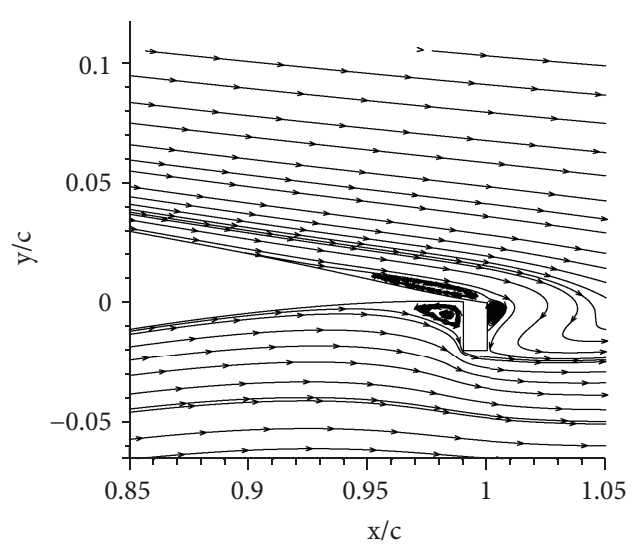

(b) GF_W10

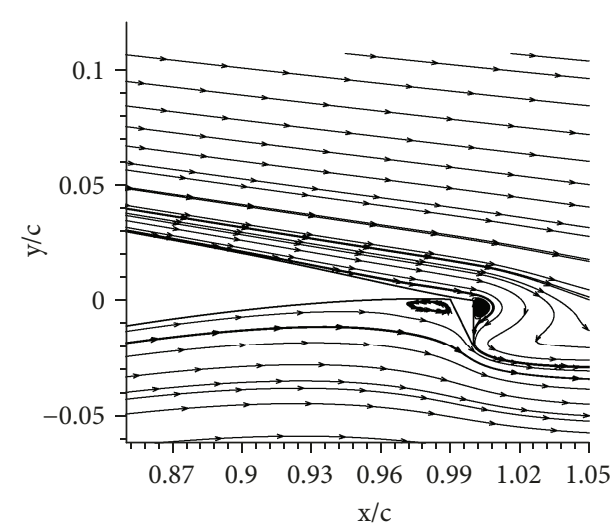

(c) GF_W10_C

FIGURE 10: Comparison of the streamlines over the airfoil trailing edge under different Gurney flap shapes $\left(\mathrm{AoA}=7.1^{\circ}\right)$. significantly reduced. The results show that the Gurney flaps are effective for suppressing the separation on the upper surface of the trailing edge and the triangular flaps are superior to the rectangular ones.

\section{Conclusions}

This article discusses the effects of different Gurney flap shapes on wind turbine blade airfoil S809. The conclusions are as follows:

(1) The rectangular Gurney flap can considerably increase the lift in both linear and nonlinear sections, while the drag and the pitching moment are concurrently increased. The Gurney flap can increase the lift-to-drag ratio of the airfoil at a small angle of attack

(2) The effect of widths of the rectangular Gurney flaps on the aerodynamic coefficients (such as the lift, the drag, and the pitching moment) is small. For GF_W2, GF_W6, and GF_W10, the maximum lift coefficients are, respectively, increased by $20.65 \%$, $20.29 \%$, and $16.31 \%$

(3) The effect of the triangular flaps is conspicuously better than that of the rectangular flaps. Triangular Gurney flap GF_W10_C is the best, whose maximum lift coefficient is increased by $28.42 \%$

\section{Nomenclature}
c: Chord
Cl: Lift coefficient
Cd: Drag coefficient
Cm: Moment coefficient
Cp: Pressure coefficient
AoA: Angle of attack
$\mathrm{K}: \quad$ Lift-to-drag ratio.

\section{Data Availability}

The data used to support the findings of this study are available from the corresponding author upon request.

\section{Conflicts of Interest}

The authors declare that there is no conflict of interests regarding the publication of this paper.

\section{Acknowledgments}

The present work is supported by the National Natural Science Foundation of China (11502214) and the Fund of the National Key Laboratory of Aerodynamic Design and Research (2018KC010117). The authors would like to express their gratitude to Chun $\mathrm{Na} \mathrm{Li}$ and Yi Dong Guo in Northwestern Polytechnical University for their valuable guidance. 


\section{References}

[1] R. H. Liebeck, "Design of subsonic airfoils for high lift," Journal of Aircraft, vol. 15, no. 9, pp. 547-561, 1978.

[2] G. Guzel, L. N. Sankar, and M. Rhee, "Computational investigation of the effects of Gurney flap on the aerodynamic performance of VR-12 airfoil," in 23rd AIAA Applied Aerodynamics Conference, p. 4960, Toronto, ON, Canada, 2005.

[3] H. Li-shu, G. Chao, S. Wen-Ping, and S. Ke, "Airfoil flow control using vortex generators and a Gurney flap," Proceedings of the Institution of Mechanical Engineers, Part C: Journal of Mechanical Engineering Science, vol. 227, no. 12, pp. 27012706, 2013.

[4] M. S. Chandrasekhara, P. B. Martin, and C. Tung, "Compressible dynamic stall performance of a variable droop leading edge airfoil with a Gurney flap," in 42nd AIAA Aerospace Sciences Meeting and Exhibit, p. 41, Reno, NV, USA, 2004.

[5] B. S. Lee, K. Yee, W. Joo, and D. H. Lee, "Passive control of dynamic stall via nose droop with Gurney flap," in 43rd AIAA Aerospace Sciences Meeting and Exhibit, p. 1364, Reno, NV, USA, 2005.

[6] S. Bieniawski and I. M. Kroo, "Flutter suppression using micro-trailing edge effectors," in 44th AIAA/ASME/ASCE/AHS/ASC Structures, Structural Dynamics, and Materials Conference, p. 1941, Norfolk, VA, USA, 2003.

[7] Y. H. Xie, W. Jiang, K. Lu, and D. Zhang, "Numerical investigation into energy extraction of flapping airfoil with Gurney flaps,” Energy, vol. 109, pp. 694-702, 2016.

[8] C. Cravero, "Aerodynamic performance prediction of a profile in ground effect with and without a Gurney flap," Journal of Fluids Engineering, vol. 139, no. 3, article 031105, 2017.

[9] D. T. Yen Nakafuji, C. P. van Dam, J. Michel, and P. Morrison, "Load control for turbine blades: a non-traditional microtab approach," in ASME 2002 Wind Energy Symposium, pp. 321330, Reno, NV, USA, 2002.

[10] A. M. Cooperman, R. Chow, and C. P. van Dam, "Active load control of a wind turbine airfoil using microtabs," Journal of Aircraft, vol. 50, no. 4, pp. 1150-1158, 2013.

[11] K.-C. Tsai, C. T. Pan, A. Cooperman, S. Johnson, and C. van Dam, "An innovative design of a microtab deployment mechanism for active aerodynamic load control," Energies, vol. 8, no. 6, pp. 5885-5897, 2015.

[12] C. L. Bottasso, A. Croce, F. Gualdoni, and P. Montinari, "Load mitigation for wind turbines by a passive aeroelastic device," Journal of Wind Engineering and Industrial Aerodynamics, vol. 148, pp. 57-69, 2016.

[13] M. Suresh and N. Sitaram, "Effects of Gurney flap configuration on the performance of a centrifugal fan," Journal of Applied Fluid Mechanics, vol. 12, no. 2, pp. 565-571, 2019.

[14] J. J. Wang, Y. C. Li, and K. S. Choi, "Gurney flap-lift enhancement, mechanisms and applications," Progress in Aerospace Sciences, vol. 44, no. 1, pp. 22-47, 2008.

[15] J. A. Cole, B. A. O. Vieira, J. G. Coder, A. Premi, and M. D. Maughmer, "Experimental investigation into the effect of Gurney flaps on various airfoils," Journal of Aircraft, vol. 50, no. 4, pp. 1287-1294, 2013.

[16] R. Myose, M. Papadakis, and I. Heron, "A parametric study on the effect of Gurney flaps on single and multi-element airfoils, three-dimensional wings, and reflection plane model," in 35th Aerospace Sciences Meeting and Exhibit, p. 34, Reno, NV, USA, 1997.
[17] P. Nikoueeyan, J. A. Strike, A. S. Magstadt, M. D. Hind, and J. W. Naughton, "Characterization of the aerodynamic coefficients of a wind turbine airfoil with a Gurney flap for flow control applications," in 32nd AIAA Applied Aerodynamics Conference, p. 2146, Atlanta, GA, USA, 2014.

[18] X. He, J. J. Wang, M. Q. Yang, D. L. Ma, C. Yan, and P. Q. Liu, "Numerical simulation of Gurney flaps lift-enhancement on a low Reynolds number airfoil," Science China Technological Sciences, vol. 60, no. 10, pp. 1548-1559, 2017.

[19] M. Graham, A. Muradian, and L. W. Traub, "Experimental study on the effect of Gurney flap thickness on airfoil performance," Journal of Aircraft, vol. 55, no. 2, pp. 897-902, 2018.

[20] D. M. Somers, Design and Experimental Results for the S809 Airfoil, National Renewable Energy Lab., 1997.

[21] H. Y. Xu, C. L. Qiao, and Z. Y. Ye, "Dynamic stall control on the wind turbine airfoil via a co-flow jet," Energies, vol. 9, no. 6 , p. $429,2016$. 


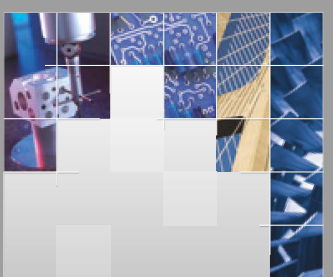

\section{Enfincering}
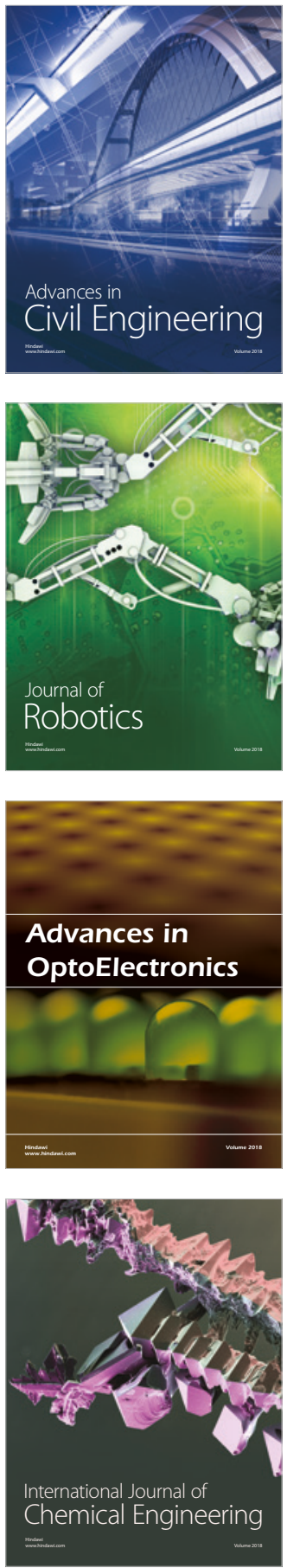

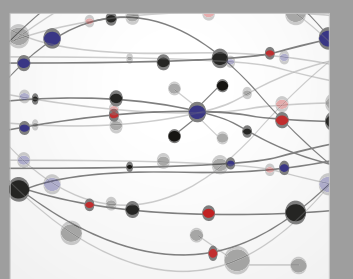

\section{Rotating \\ Machinery}

The Scientific World Journal

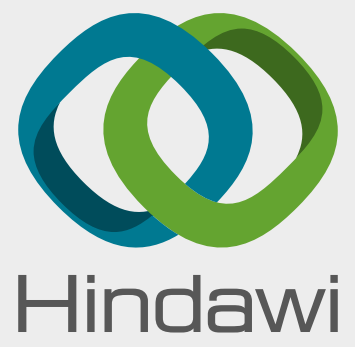

Submit your manuscripts at

www.hindawi.com
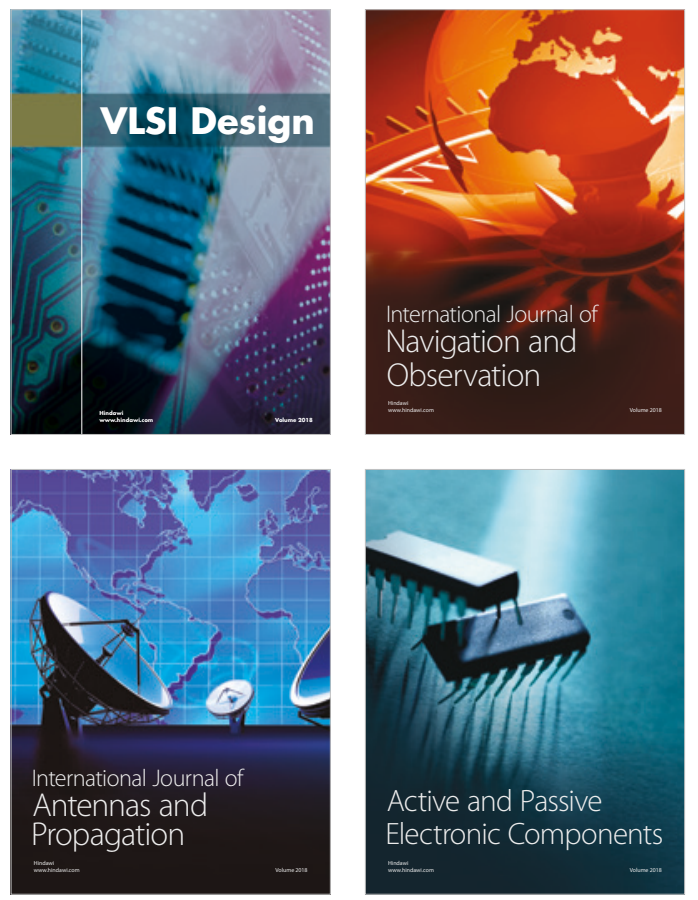
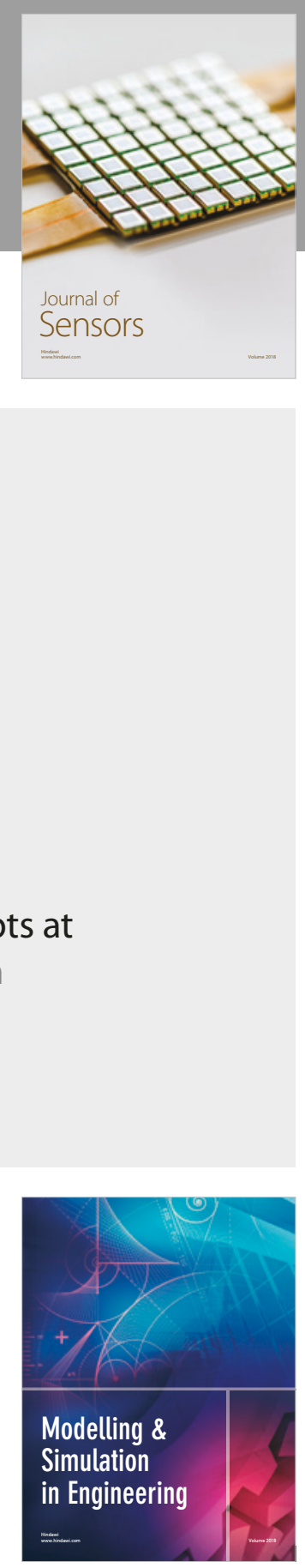

\section{Advances \\ Multimedia}
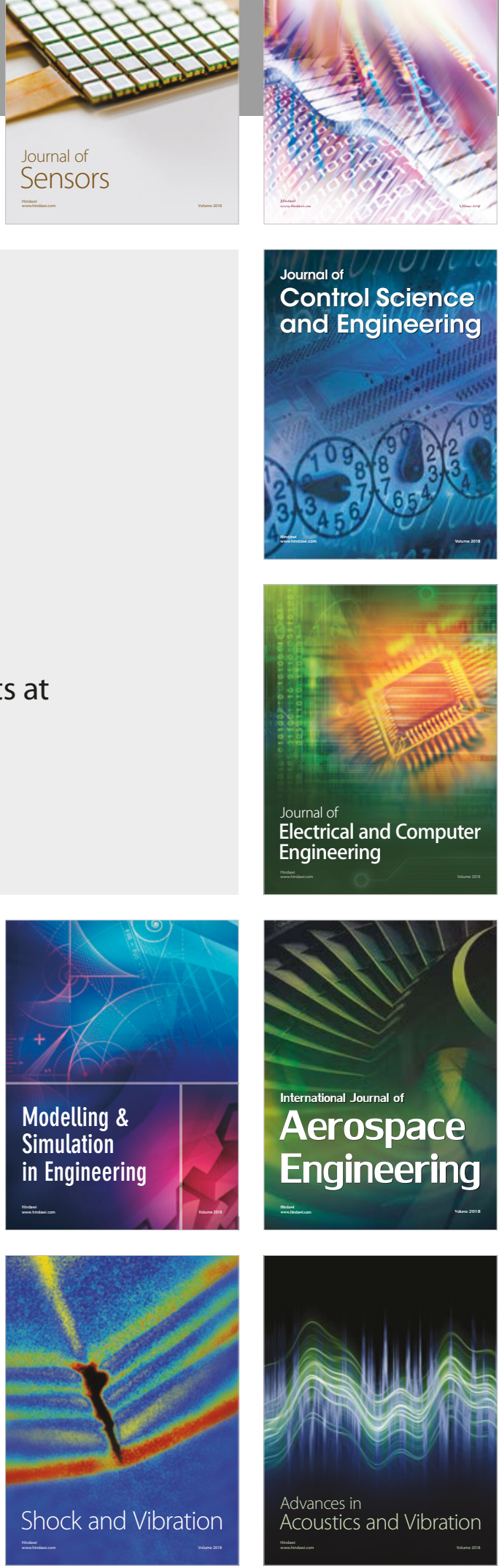